\title{
Antibiotic use and colorectal neoplasia: a systematic review and meta-analysis
}

\author{
Chino Aneke-Nash (D , ${ }^{1}$ Garrett Yoon, ${ }^{1}$ Mengmeng Du, ${ }^{2}$ Peter Liang ${ }^{1,3}$
}

To cite: Aneke-Nash C, Yoon G, Du $\mathrm{M}$, et al. Antibiotic use and colorectal neoplasia: a systematic review and metaanalysis. BMJ Open Gastro 2021;8:e000601. doi:10.1136/ bmjgast-2021-000601

- Additional supplemental material is published online only. To view, please visit the journal online (http://dx.doi. org/10.1136/bmjgast-2021000601).

Received 18 January 2021 Revised 14 April 2021 Accepted 25 April 2021

\section{Check for updates}

(C) Author(s) (or their employer(s)) 2021. Re-use permitted under CC BY-NC. No commercial re-use. See rights and permissions. Published by BMJ.

${ }^{1}$ Department of Medicine, NYU Langone Medical Center, New York, New York, USA

${ }^{2}$ Epidemiology and Biostatistics, Memorial Sloan Kettering Cancer Center, New York, New York, USA

${ }^{3}$ Division of Gastroenterology, VA NY Harbor Healthcare System Manhattan Campus Veterans Learning Resources Center, New York, New York, USA

Correspondence to Dr Chino Aneke-Nash; chino.aneke-nash@nyumc.org

\section{ABSTRACT}

Background and aims Colorectal cancer (CRC) is the third most common cancer for women and men and the second leading cause of cancer death in the USA. There is emerging evidence that the gut microbiome plays a role in CRC development, and antibiotics are one of the most common exposures that can alter the gut microbiome. We performed a systematic review and meta-analysis to characterise the association between antibiotic use and colorectal neoplasia.

Methods We searched PubMed, EMBASE, and Web of Science for articles that examined the association between antibiotic exposure and colorectal neoplasia (cancer or adenoma) through 15 December 2019. A total of 6031 citations were identified and 6 papers were included in the final analysis. We assessed the association between the level of antibiotic use (defined as number of courses or duration of therapy) and colorectal neoplasia using a random effects model.

Results Six studies provided 16 estimates of the association between level of antibiotic use and colorectal neoplasia. Individuals with the highest levels of antibiotic exposure had a $10 \%$ higher risk of colorectal neoplasia than those with the lowest exposure (effect size: $1.10,95 \% \mathrm{Cl} 1.01$ to 1.18$)$. We found evidence of high heterogeneity $\left(l^{2}=79 \%, p=0.0001\right)$ but not of publication bias.

Conclusions Higher levels of antibiotic exposure is associated with an increased risk of colorectal neoplasia. Given the widespread use of antibiotics in childhood and early adulthood, additional research to further characterise this relationship is needed.

\section{INTRODUCTION}

Colorectal cancer (CRC) is the second leading cause of cancer death worldwide, ${ }^{1}$ and the incidence is increasing among younger adults in a number of countries. ${ }^{2}$ It has been hypothesised that antibiotics may play a role in CRC pathogenesis through its effects on the gut microbiome. ${ }^{3-6}$ Antibiotics are thought to induce a change in the composition of the gut microbiome and create a proinflammatory state that promotes the formation of cancer cells. ${ }^{78}$ Several bacterial species have been implicated in CRC pathogenesis, most notably Fusobacterium nucleatum. ${ }^{9-13}$ Quantitative PCR experiments have shown that patients with CRC have increased proinflammatory bacteria in their stool compared with healthy controls. ${ }^{4}$ Similarly, other established CRC risk factors such as red and processed meat consumption are also associated with overgrowth of proinflammatory bacteria in the gut. ${ }^{1415}$

Although antibiotics are one of the most commonly prescribed type of medications worldwide, $^{16-18}$ the association between antibiotic use and colorectal neoplasia (adenoma or cancer) has not been clearly delineated. ${ }^{19-21}$ Therefore, we conducted a systematic review and meta-analysis to quantify the relationship between antibiotic use and development of colorectal neoplasia in adults.

\section{MATERIALS AND METHODS}

Study selection and inclusion/exclusion criteria We followed the Preferred Reporting Items for Systematic Reviews and Meta-Analyses guidelines to conduct the search and review. ${ }^{22}$ Two authors (CA-N and GY) independently searched PubMed, Web of Science, and Embase. The search was conducted from inception of each database until 15 December 2019 without language restrictions, using predetermined search criteria. The search terms were the following for PubMed: ("Colonic Neoplasms"[Mesh] OR "Rectal Neoplasms"[Mesh] OR "Polyps"[Mesh] OR "Adenomatous Polyps"[Mesh] OR "Colorectal Neoplasms"[Mesh] OR "Colonic Neoplasms" or "Colonic Neoplasm" or "Rectal Neoplasms" or "Rectal Neoplasm" or "Adenomatous Polyps" or "Adenomatous Polyp" or "Colon Cancer" or "Rectal Cancer" or "Polyps" or "Polyp") AND ("Anti-Bacterial Agents"[Mesh] OR "Anti-Bacterial Agents" OR "Anti-Bacterial Agent" OR "Antibiotic" OR “Antibiotics"). Similar terms were used for database searches on Embase and Web of Science (online supplemental table 1). Titles and abstracts were screened by the same two authors, and disagreements were resolved by a third author (PL). Only human 
observational studies that provided a risk estimate for the association between antibiotics and colorectal adenoma or cancer were included. There were no restrictions on the age of study participants. Studies on any class of antibiotics prescribed for any indication were included, if the endpoint was colorectal adenoma or cancer. Studies were excluded if they did not assess antibiotic exposure or the development of colorectal neoplasia. All in vitro and animal studies were excluded. The main outcomes of interest were the associations between ever versus never and highest versus lowest antibiotic use and colorectal neoplasia.

\section{Data extraction}

We extracted the following data for all studies: country, year of publication, study design, participant age, data source, sample size, inclusion and exclusion criteria, type and duration of antibiotic exposure, duration of follow-up, confounders included in the models, and neoplasia outcome. We chose the risk estimate for all antibiotics combined rather than specific antibiotic classes when available. Adjusted OR and 95\% CI relative to never users or the lowest level of exposure were recorded.

\section{Quality assessment}

The Newcastle-Ottawa Scale (NOS) was used to ascertain the risk of bias in three categories: selection of study groups, comparability of the groups, and ascertainment of exposures. ${ }^{23}$ Two authors (CA-N and GY) independently assessed each study and a third author (PL) resolved any disagreement. Studies with 7-9 points on the NOS were considered good quality, while those with 4-6 points and 0-3 points were considered fair and low quality, respectively.

\section{Statistical analysis}

We used a random effects model using the Dersimonian and Laird method to compute the effect size and 95\% CI for any lifetime antibiotic use versus no antibiotic use and for the comparison between the highest users of antibiotics and those who had no antibiotic use. The estimate of heterogeneity was taken from the Mantel-Haenszel model. A sensitivity analysis was conducted excluding one study that measured adenoma instead of cancer as the outcome. We evaluated for heterogeneity using the $\mathrm{I}^{2}$ statistic and considered values of $25 \%, 50 \%$, and $75 \%$ as low, moderate and high heterogeneity, respectively. ${ }^{24}$ Begg's test, Egger's test, and the funnel plot were used to assess for publication bias both visually and using statistics. Statistical significance for heterogeneity and publication bias was set at $\mathrm{p}<0.05$. All analyses were performed with Stata/IC V.12.1 for Mac.

\section{RESULTS}

\section{Exclusion strategy}

Our search identified 6031 studies. Articles were excluded if they studied animal models $(\mathrm{n}=31)$, did not examine antibiotic exposure $(\mathrm{n}=1964)$, did not measure colorectal neoplasia $(n=158)$, or made no reference to either the exposure or outcome of interest $(n=3826)$. After the title screen, we reviewed 16 abstracts, 10 of which examined antibiotic prophylaxis prior to CRC resection to prevent postoperative infection. These studies were excluded and the remaining six manuscripts were included in the analysis (figure 1).

\section{Description of studies}

Table 1 shows details of the six included studies. Four were nested case-control studies drawn from large population databases based in the UK, the Netherlands, and Taiwan. ${ }^{25-28}$ The other two were cohort studies based in the USA and Finland. ${ }^{29}{ }^{30}$ The outcome was colon and rectal cancer in three studies, ${ }^{26-28}$ CRC in two studies, ${ }^{25} 29$ and adenoma in one study. ${ }^{30}$ Except for two studies that respectively examined diabetics and female nurses, ${ }^{27} 30$ the others were representative of the general population. A total of 73405 cases of colorectal neoplasia were identified from over 4 million participants, and the median duration of follow-up ranged from 5 to 8.1 years. All studies analysed the association between antibiotic exposure and colorectal neoplasia with adjustment for relevant covariates, although how exposure was ascertained and quantified differed by study. When risk estimates based on both number of prescriptions and cumulative dose were presented, we selected the former. Of the six studies (table 1), exposure was defined as number of prescriptions or courses in four studies ${ }^{25-27} 29$ and duration of use in two studies. ${ }^{28}{ }^{30}$ Three of the six studies also reported exposures to anti-anaerobic and antiaerobic antibiotics separately. ${ }^{27-29}$ One study measured exposure during two different age ranges (20-39 years vs $40-59$ years), ${ }^{30}$ and we only included the estimate for the younger age range because we assumed a priori that exposure in earlier adulthood is of greater importance to carcinogenesis later in life. All studies were of good quality, with scores of $7-8$ on the NOS. Therefore, we did not perform any sensitivity analysis or meta-regression based on study quality.

\section{Risk of colorectal neoplasia among users of antibiotics}

Only a single study of individuals with diabetes in Taiwan assessed the relationship between ever versus never antibiotic exposure and colorectal neoplasia. ${ }^{27}$ The authors found any antibiotic use was not significantly associated with colon (effect size (ES): 1.06, 95\% CI 0.89 to 1.26 ) or rectal cancer (ES: $0.98,95 \%$ CI 0.8 to 1.2 ).

The remaining studies all reported risk estimates based on level of antibiotic exposure. Compared with individuals with the lowest level of antibiotic exposure, those with the highest level of exposure, as defined in table 1, had a $10 \%$ higher risk of colorectal neoplasia (ES: 1.10, 95\% CI 1.01 to $1.18, \mathrm{I}^{2}=79 \%, \mathrm{n}=15$ ) (figure 2 ). Visual inspection of the funnel plot generated from the Begg's test showed no evidence of publication bias (figure 3). Similarly, the Egger's test showed no evidence of publication 


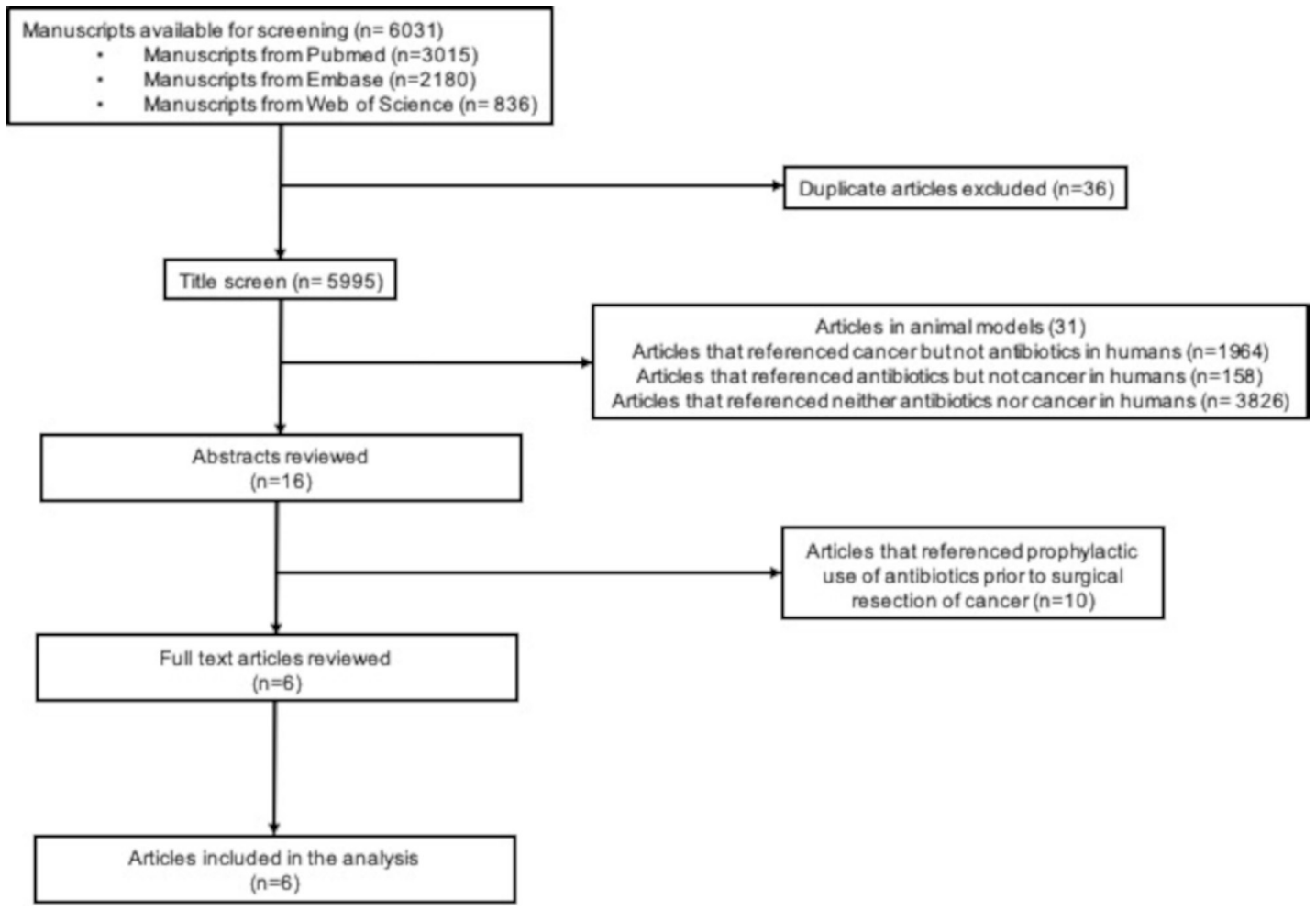

Figure 1 Flow diagram of study selection.

bias $(p=0.24)$. A sensitivity analysis excluding the study by Cao et $a l^{30}$ that examined adenoma rather than cancer showed similar results (ES: $1.08,95 \%$ CI 1.001 to 1.17 , $\left.\mathrm{I}^{2}=81 \%, \mathrm{n}=14\right)$.

\section{Risk of CRC among those who used anti-anaerobic antibiotics versus anti-aerobic antibiotics}

In the three studies that distinguished anti-anaerobic versus anti-aerobic agents, ${ }^{27-29}$ the risk for cancer appeared stronger for anti-anaerobic compared with anti-aerobic agents and for colon compared with rectal cancer (table 2). For example, in the study by Wang et $a l,{ }^{27}$ the risk of colon cancer in those who ever used antianaerobic antibiotics was twofold higher than never users (ES: 2.31, 95\% CI 2.12 to 2.52), while there was no difference for ever versus never users for anti-aerobic agents (ES: $0.94,95 \%$ CI 0.79 to 1.12 ).

\section{Time between antibiotic exposure and CRC risk}

Three of the studies also examined timing of antibiotic exposure and the risk of colorectal neoplasia. ${ }^{28-30}$ Two studies found that antibiotic use more than 10 years prior to diagnosis was associated with an increased risk of colorectal neoplasia, but there was no increased risk associated with antibiotic use 5 years before diagnosis. ${ }^{28} 30$ In the study by Zhang et $a l,{ }^{28}$ antibiotic use more than 10 years prior to colon cancer diagnosis was associated with greater risk (ES: 1.17, 95\% CI 1.06 to 1.31 ) than no use, but there was no difference for antibiotic use within the 10 years preceding diagnosis (ES: 1.00 , 95\% CI 0.89 to 1.10). Similarly, the third study found that CRC risk was slightly increased in individuals who used antibiotics 3-8 years (ES: $1.37,95 \%$ CI: 1.10 to 1.70$)$ vs $2-7$ years prior to diagnosis (ES: $1.33,95 \%$ CI: 1.08 to 1.64$).^{29}$

\section{DISCUSSION}

In this systematic review and meta-analysis of six observational studies with more than 4 million participants, we found that individuals with the highest level of exposure to antibiotics were $10 \%$ more likely to develop colorectal neoplasia compared with those with the lowest exposure. In addition, based on a subset of studies, the association seems stronger for earlier exposure, anti-anaerobic agents, and colon rather than rectal cancer.

Although the role of antibiotics in the pathogenesis of colorectal neoplasia is not entirely clear, our main finding appears biologically plausible based on some potential mechanisms that have been previously described. Animal experiments have shown that antibiotic use, especially early in life, leads to loss of biodiversity in the colonic microbiome and long-lasting metabolic derangements. ${ }^{31}$ Antibiotics change the gut microbiome by promoting the growth of proinflammatory bacteria that increase the production of reactive oxygen species, creating a microenvironment that promotes tumour formation. ${ }^{101132}$ F. nucleatum, one of the most well-studied anaerobic bacteria, produces a cell surface protein that aids in attachment to the colonic epithelial cells. Gene expression studies show that this cell surface protein is overexpressed in human CRC cells compared with adjacent normal tissue from the same individuals. ${ }^{33} 34$ Fusobacterium has also been identified in distant metastatic cells in patients with CRG. ${ }^{35}$ Other anaerobic bacteria 


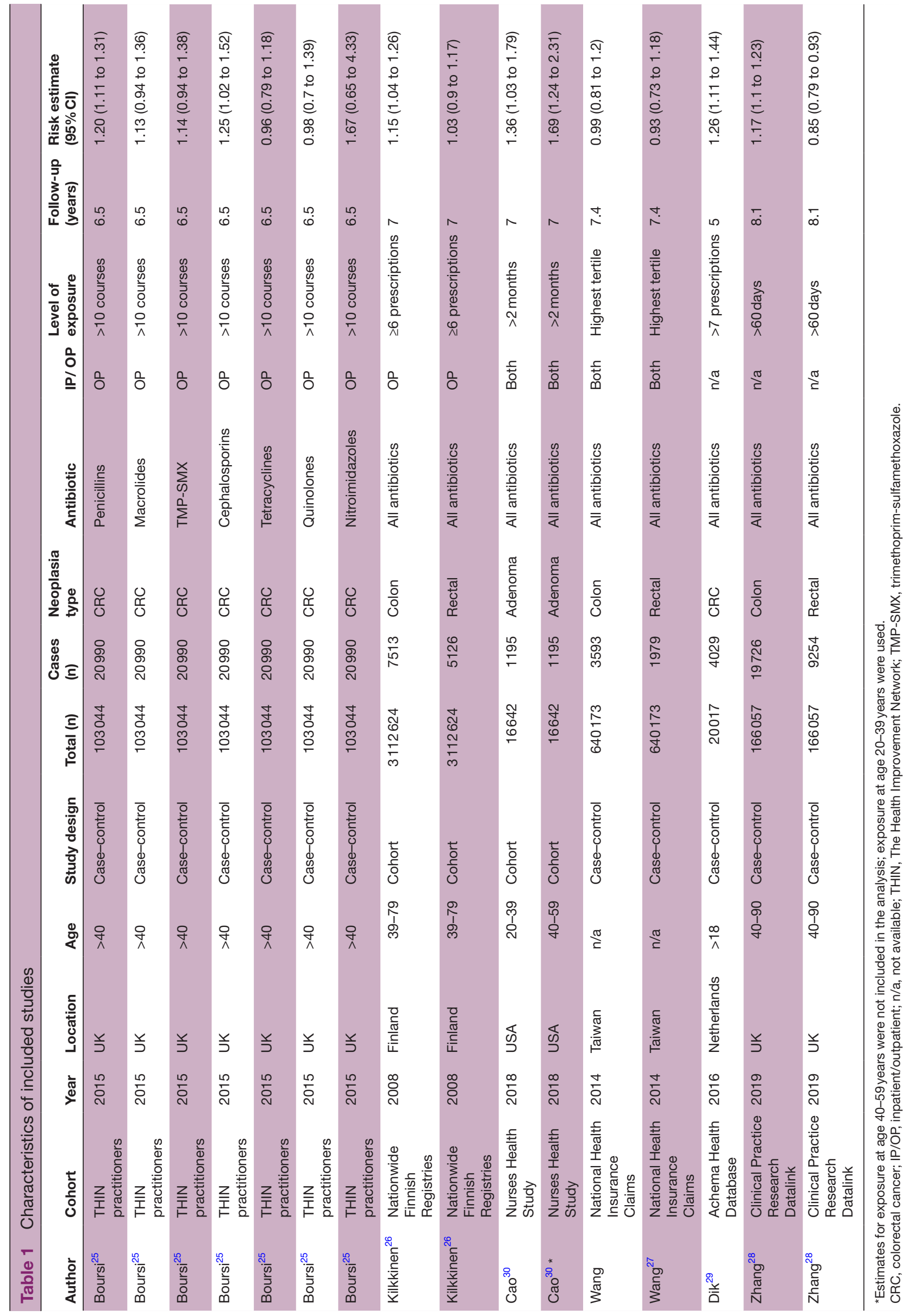




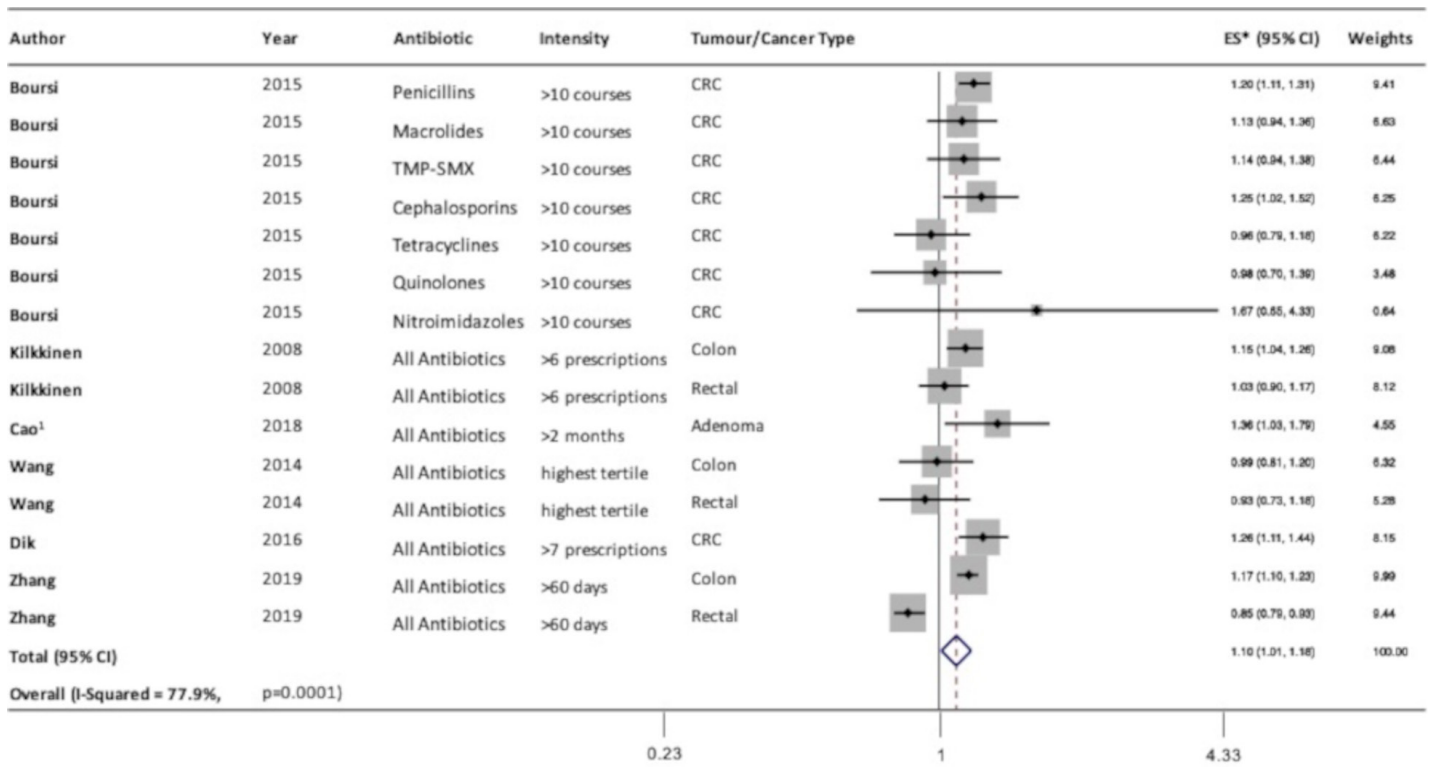

Figure 2 Forest plot of the association between highest versus lowest antibiotic exposure and colorectal neoplasia. ${ }^{1}$ Estimates for exposure at age 20-39 years were used. CRC, colorectal cancer; ES, effect size; TMP-SMX, trimethoprimsulfamethoxazole.

have also been implicated. For example, enterotoxigenic Bacteroides fragilis produces toxins that are abundant in the stool of patients with CRC and more so in advanced disease. ${ }^{36}$ Genetic analysis has also found an overexpression of the enterotoxin gene in pre-malignant tissue compared with normal colonic tissue. ${ }^{3738}$

The small number of available studies precluded us from formally assessing the relationship between timing of exposure or antibiotic class and colorectal neoplasia. However, given the long lag time between exposure to established risk factors such as smoking and CRC development, ${ }^{39}$ it seems entirely plausible that earlier exposure to antibiotics may also increase risk. The suggestion that anti-anaerobic antibiotics may have a greater association with CRC than anti-aerobic antibiotics likely indicates the greater impact of the former on the predominantly anaerobic gut microbiome. ${ }^{40}$ In the three studies that

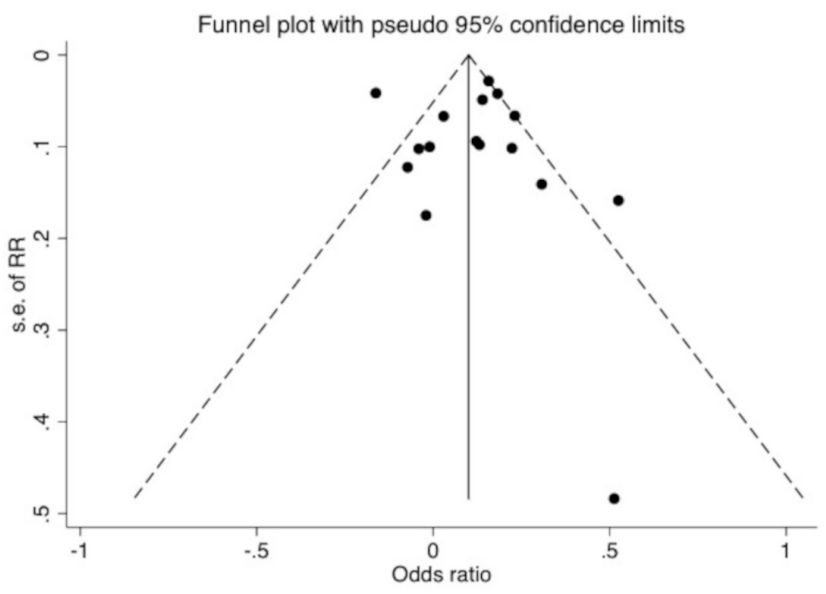

Figure 3 Funnel plot of level of antibiotic exposure and risk of colorectal neoplasia. RR, relative risk. presented estimates for colon and rectal cancer separately, two studies found a significant association between high levels of exposure to antibiotics and colon cancer but not rectal cancer. ${ }^{26}{ }^{28}$ The third study found no association between antibiotic use and colon or rectal cancer overall, but for anti-anaerobic agents a significant association was observed for colon but not rectal cancer. ${ }^{27}$ These findings suggest the risk of antibiotic exposure may differ for colon and rectal cancer.

A major strength of this paper is the group of large population-based studies that were included in the analysis. Most of the studies used data prospectively collected from electronic health records over many years, which minimises recall bias. However, several limitations should be noted. First, because antibiotic dose was categorised differently by study, we were unable to precisely quantify the relationship between level of exposure and neoplasia risk across all studies. Pooling various categories of high versus low exposure provided a useful framework to conduct the analysis but inherently decreases the precision of the estimate. Therefore, the magnitude of association in the summary estimate should be interpreted with caution. Furthermore, as with all observational studies, association does not prove causation. Second, most of the studies measured the dose of prescribed antibiotics, which does not account for medication adherence. Third, because most studies used outpatient data that only included oral antibiotics, we had insufficient data to stratify the results by oral versus parenteral route of administration. Fourth, the variability in geographical location and time period during which antibiotic exposure was ascertained raises the possibility that drug formulation and dosage may be different in the studies. Fifth, all included studies were conducted in developed nations, which use antibiotics more frequently than developing 
Table 2 Level of aerobic versus anti-anaerobic antibiotic use and risk of colorectal cancer

\begin{tabular}{|c|c|c|c|c|}
\hline Author & Outcome & Level of exposure & $\begin{array}{l}\text { Anti-anaerobic agents, } \\
\text { ES }(95 \% \mathrm{CI})\end{array}$ & $\begin{array}{l}\text { Anti-aerobic agents, } \\
\text { ES }(95 \% \mathrm{Cl})\end{array}$ \\
\hline Zhang $^{28}$ & Colon & 0 days & Reference & Reference \\
\hline Zhang $^{28}$ & Colon & $16-30$ days & $1.10(1.04$ to 1.16$)$ & $1.11(1.03$ to 1.20$)$ \\
\hline Zhang $^{28}$ & Colon & 31-60 days & $1.12(1.06$ to 1.19$)$ & $1.00(0.90$ to 1.12$)$ \\
\hline Zhang $^{28}$ & Rectal & $1-15$ days & 1.01 (0.95 to 1.07$)$ & $0.96(0.90$ to 1.03$)$ \\
\hline Zhang $^{28}$ & Rectal & 16-30 days & $0.96(0.89$ to 1.04$)$ & $0.92(0.81$ to 1.05$)$ \\
\hline Zhang $^{28}$ & Rectal & $31-60$ days & $0.97(0.89$ to 1.06$)$ & $0.84(0.70$ to 1.01$)$ \\
\hline Zhang $^{28}$ & Rectal & $>60$ days & $0.88(0.80$ to 0.97$)$ & $0.84(0.68$ to 1.03$)$ \\
\hline Wang $^{27}$ & Colon & $\begin{array}{l}\text { Second tertile of number of } \\
\text { prescriptions }\end{array}$ & 1.90 (1.67 to 2.16$)$ & 0.99 (0.82 to 1.20$)$ \\
\hline Wang $^{27}$ & Colon & $\begin{array}{l}\text { Highest tertile of number of } \\
\text { prescriptions }\end{array}$ & 1.27 (1.10 to 1.46$)$ & $0.77(0.63$ to 0.94$)$ \\
\hline Wang $^{27}$ & Rectal & No use & Reference & Reference \\
\hline Wang $^{27}$ & Rectal & Any use & 1.69 (1.50 to 1.90$)$ & $0.93(0.76$ to 1.14$)$ \\
\hline Wang $^{27}$ & Rectal & $\begin{array}{l}\text { Lowest tertile of number of } \\
\text { prescriptions }\end{array}$ & 2.47 (2.13 to 2.86$)$ & 0.88 (0.71 to 1.09$)$ \\
\hline $\operatorname{Dik}^{29}$ & CRC & 5-7 prescriptions & $\mathrm{n} / \mathrm{a}$ & 1.09 (0.95 to 1.25$)$ \\
\hline $\mathrm{Dik}^{29}$ & CRC & 8 or more prescriptions & $\mathrm{n} / \mathrm{a}$ & 1.25 (1.08 to 1.45$)$ \\
\hline $\mathrm{Dik}^{29}$ & $\mathrm{CRC}$ & 5 or more prescriptions & 1.45 (1.07 to 1.97$)$ & $\mathrm{n} / \mathrm{a}$ \\
\hline
\end{tabular}

CRC, colorectal cancer; ES, effect size; n/a, not available.

nations. ${ }^{19}$ Although data from developing nations are lacking, there is no reason to suspect the pathophysiology would differ by geography. Sixth, the inter-relation between antibiotic use and CRC may be susceptible to confounding by indication. Chronic bacterial infection of the colon can cause inflammatory changes, ${ }^{41-43}$ a well-known risk factor for colon cancer. Therefore, the carcinogenesis attributed to the hypothesised remodelling of the gut microbiome through antibiotic administration may actually be mediated by inflammation. However, data from in vitro and animal studies suggest that antibiotics change the microbiome by increasing the growth of bacteria that promote a proinflammatory environment which promotes tumour formation. ${ }^{10} 113132$ Lastly, we observed a high level of heterogeneity, which is likely due to differences in study design and patient population. We used a random effects model to partially account for these variations. While there was no evidence of publication bias, the power to detect bias is low when sample sizes are small. ${ }^{44}$

Those with the highest exposure to antibiotics had the greatest risk of colorectal neoplasia when compared with those who used antibiotics the least. Short-term effects of antibiotic use such as Clostridium difficile infection and drug resistance have long been recognised. However, our results add to accumulating evidence that repeated use of antibiotics may also increase the risk of colorectal neoplasia. This highlights the importance of antibiotic stewardship in order to minimise inappropriate use. 
In summary, a systematic review and meta-analysis found that individuals with the highest exposure to antibiotics were moderately more likely to develop colorectal neoplasia compared with those with the lowest exposure. These results support the proposed mechanism of antibiotics leading to gut dysbiosis and subsequent carcinogenesis. Further studies are needed to delineate whether neoplasia risk differs for specific classes of antibiotics.

Acknowledgements The authors would like to thank the New York University Library and librarians for their help with gaining access to the databases used in this study.

Contributors PL developed the research hypothesis and all the authors participated in conference calls to develop the research plan. CA-N and GY each independently searched all three databases for manuscripts matching the predetermined criteria. CA-N conducted the analysis and wrote the manuscript. All authors provided comments used to finalise the manuscript. CA-N submitted the manuscript to the journal.

Funding MD is supported by grant P30 CA008748 from the National Cancer Institute. PL is supported by grant K08 CA230162 from the National Cancer Institute.

Disclaimer This material is the result of work supported in part by resources from the Veterans Health Administration. The views expressed in this article are those of the authors and do not represent the views of the Department of Veterans Affairs.

Competing interests None declared.

Patient consent for publication Not required.

Provenance and peer review Not commissioned; externally peer reviewed.

Data availability statement Data are available in a public, open access repository. Data used were only published data.

Supplemental material This content has been supplied by the author(s). It has not been vetted by BMJ Publishing Group Limited (BMJ) and may not have been peer-reviewed. Any opinions or recommendations discussed are solely those of the author(s) and are not endorsed by BMJ. BMJ disclaims all liability and responsibility arising from any reliance placed on the content. Where the content includes any translated material, BMJ does not warrant the accuracy and reliability of the translations (including but not limited to local regulations, clinical guidelines, terminology, drug names and drug dosages), and is not responsible for any error and/or omissions arising from translation and adaptation or otherwise.

Open access This is an open access article distributed in accordance with the Creative Commons Attribution Non Commercial (CC BY-NC 4.0) license, which permits others to distribute, remix, adapt, build upon this work non-commercially, and license their derivative works on different terms, provided the original work is properly cited, appropriate credit is given, any changes made indicated, and the use is non-commercial. See: http://creativecommons.org/licenses/by-nc/4.0/.

\section{ORCID iD}

Chino Aneke-Nash http://orcid.org/0000-0002-6372-2428

\section{REFERENCES}

1 Sung H, Ferlay J, Siegel RL, et al. Global cancer statistics 2020: GLOBOCAN estimates of incidence and mortality worldwide for 36 cancers in 185 countries. CA Cancer J Clin 2021. doi:10.3322/ caac.21660. [Epub ahead of print: 04 Feb 2021].

2 Siegel RL, Torre LA, Soerjomataram I, et al. Global patterns and trends in colorectal cancer incidence in young adults. Gut 2019;68:2179-85.

3 Marchesi JR, Dutilh BE, Hall N, et al. Towards the human colorectal cancer microbiome. PLoS One 2011;6): :e20447.

4 Ahn J, Sinha R, Pei Z, et al. Human gut microbiome and risk for colorectal cancer. J Natl Cancer Inst 2013;105:1907-11.

5 Donohoe DR, Garge N, Zhang X, et al. The microbiome and butyrate regulate energy metabolism and autophagy in the mammalian colon. Cell Metab 2011;13): :517-26.

6 Zackular JP, Baxter NT, Iverson KD, et al. The gut microbiome modulates colon tumorigenesis. mBio 2013;4:e00692-13.

7 Lange K, Buerger M, Stallmach A, et al. Effects of antibiotics on gut microbiota. Dig Dis 2016;34:260-8.
8 Blaser MJ. Antibiotic use and its consequences for the normal microbiome. Science 2016;352:544-5.

9 Castellarin M, Warren RL, Freeman JD, et al. Fusobacterium nucleatum infection is prevalent in human colorectal carcinoma. Genome Res 2012;22:299-306.

10 Kostic AD, Chun E, Robertson L, et al. Fusobacterium nucleatum potentiates intestinal tumorigenesis and modulates the tumorimmune microenvironment. Cell Host Microbe 2013;14:207-15.

11 Kostic AD, Gevers D, Pedamallu CS, et al. Genomic analysis identifies association of Fusobacterium with colorectal carcinoma. Genome Res 2012;22:292-8.

12 Wu Y, Wu J, Chen T, et al. Fusobacterium nucleatum potentiates intestinal tumorigenesis in mice via a Toll-like receptor 4/p21Activated kinase 1 cascade. Dig Dis Sci 2018;63:1210-8.

13 Yang Y, Weng W, Peng J, et al. Fusobacterium nucleatum increases proliferation of colorectal cancer cells and tumor development in mice by activating Toll-like receptor 4 signaling to nuclear Factor$\kappa \mathrm{B}$, and up-regulating expression of microRNA-21. Gastroenterology 2017;152:e24:p. 851-866.

14 Vipperla K, O'Keefe SJ. The microbiota and its metabolites in colonic mucosal health and cancer risk. Nutr Clin Pract 2012;27:624-35.

15 Ou J, Carbonero F, Zoetendal EG, et al. Diet, microbiota, and microbial metabolites in colon cancer risk in rural Africans and African Americans. Am J Clin Nutr 2013;98:111-20.

16 Farooqui $\mathrm{HH}$, Mehta A, Selvaraj S. Outpatient antibiotic prescription rate and pattern in the private sector in India: evidence from medical audit data. PLoS One 2019;14:e0224848.

17 Yimenu DK, Emam A, Elemineh E, et al. Assessment of antibiotic prescribing patterns at outpatient pharmacy using World Health organization prescribing indicators. J Prim Care Community Health 2019;10:215013271988694.

18 Bitterman R, Hussein K, Leibovici L, et al. Systematic review of antibiotic consumption in acute care hospitals. Clin Microbiol Infect 2016;22:561.e7-561.e19.

19 Klein EY, Van Boeckel TP, Martinez EM, et al. Global increase and geographic convergence in antibiotic consumption between 2000 and 2015. Proc Natl Acad Sci U S A 2018;115:E3463-70.

20 Lee GC, Reveles KR, Attridge RT, et al. Outpatient antibiotic prescribing in the United States: 2000 to 2010. BMC Med 2014;12:96.

21 Morgan DJ, Okeke IN, Laxminarayan R, et al. Non-Prescription antimicrobial use worldwide: a systematic review. Lancet Infect Dis 2011;11:692-701.

22 Moher D, Liberati A, Tetzlaff J, et al. Preferred reporting items for systematic reviews and meta-analyses: the PRISMA statement. BMJ 2009;339:b2535

23 GA Wells, B.S, O'Connell D, Peterson J. The Newcastle-Ottawa scale (NOS) for assessing the quality of nonrandomised studies in meta-analyses 2019.

24 Higgins JPT, Thompson SG, Deeks JJ, et al. Measuring inconsistency in meta-analyses. BMJ 2003;327:557-60.

25 Boursi B, Haynes K, Mamtani R, et al. Impact of antibiotic exposure on the risk of colorectal cancer. Pharmacoepidemiol Drug Saf 2015;24:534-42.

26 Kilkkinen A, Rissanen H, Klaukka T, et al. Antibiotic use predicts an increased risk of cancer. Int J Cancer 2008;123:2152-5.

27 Wang J-L, Chang C-H, Lin J-W, et al. Infection, antibiotic therapy and risk of colorectal cancer: a nationwide nested case-control study in patients with type 2 diabetes mellitus. Int $J$ Cancer 2014;135:956-67.

28 Zhang J, Haines C, Watson AJM, et al. Oral antibiotic use and risk of colorectal cancer in the United Kingdom, 1989-2012: a matched case-control study. Gut 2019;68:1971-8.

29 Dik VK, van Oijen MGH, Smeets HM, et al. Frequent use of antibiotics is associated with colorectal cancer risk: results of a nested case-control study. Dig Dis Sci 2016;61:255-64.

30 Cao Y, Wu K, Mehta R, et al. Long-Term use of antibiotics and risk of colorectal adenoma. Gut 2018;67:672-8.

31 Cho I, Yamanishi S, Cox L, et al. Antibiotics in early life alter the murine colonic microbiome and adiposity. Nature 2012;488:621-6.

32 Tang B, Wang K, Jia Y-P, et al. Fusobacterium nucleatum-Induced impairment of autophagic flux enhances the expression of proinflammatory cytokines via ROS in Caco-2 cells. PLoS One 2016;11:e0165701

33 Strauss J, Kaplan GG, Beck PL, et al. Invasive potential of gut mucosa-derived Fusobacterium nucleatum positively correlates with IBD status of the host. Inflamm Bowel Dis 2011;17:1971-8.

34 Rubinstein MR, Wang X, Liu W, et al. Fusobacterium nucleatum promotes colorectal carcinogenesis by modulating $\mathrm{E}$-cadherin/ $\beta$ catenin signaling via its FadA adhesin. Cell Host Microbe 2013;14:195-206. 
35 Bullman S, Pedamallu CS, Sicinska E, et al. Analysis of Fusobacterium persistence and antibiotic response in colorectal cancer. Science 2017;358:1443-8.

36 Haghi F, Goli E, Mirzaei B, et al. The association between fecal enterotoxigenic $\mathrm{B}$. fragilis with colorectal cancer. BMC Cancer 2019;19:879.

37 Purcell RV, Pearson J, Aitchison A, et al. Colonization with enterotoxigenic Bacteroides fragilis is associated with early-stage colorectal neoplasia. PLoS One 2017:12:e0171602.

38 Boleij A, Hechenbleikner EM, Goodwin AC, et al. The Bacteroides fragilis toxin gene is prevalent in the colon mucosa of colorectal cancer patients. Clin Infect Dis 2015;60:208-15.

39 Liang PS, Chen T-Y, Giovannucci E. Cigarette smoking and colorectal cancer incidence and mortality: systematic review and meta-analysis. Int J Cancer 2009;124:2406-15.
40 Jahani-Sherafat S, Alebouyeh M, Moghim S, et al. Role of gut microbiota in the pathogenesis of colorectal cancer; a review article. Gastroenterol Hepatol Bed Bench 2018;11:101-9.

41 Terzić J, Grivennikov S, Karin E, et al. Inflammation and colon cancer. Gastroenterology 2010;138:2101-14.

42 Shmuely H, Passaro D, Figer A, et al. Relationship between Helicobacter pylori CagA status and colorectal cancer. Am J Gastroenterol 2001;96:3406-10.

43 Biarc J, Nguyen IS, Pini A, et al. Carcinogenic properties of proteins with pro-inflammatory activity from Streptococcus infantarius (formerly S.bovis). Carcinogenesis 2004;25:1477-84.

44 Sterne JA, Gavaghan D, Egger M. Publication and related bias in meta-analysis: power of statistical tests and prevalence in the literature. J Clin Epidemiol 2000;53:1119-29. 